\title{
Diagnostic Crossover from Obesity to Atypical Anorexia Nervosa - a Case Report
}

\author{
Heike Wolter Nora Schneider Ernst Pfeiffer Ulrike Lehmkuhl \\ Department of Child and Adolescent Psychiatry, Psychosomatics and Psychotherapy, Charité - Universitätsmedizin Berlin, Germany
}

\section{Key Words \\ Obesity · Anorexic eating behavior}

\section{Summary}

A 15-year-old, female, formerly obese adolescent was referred to our day care clinic due to self-induced massive weight loss and depressive symptoms. Intense treatment, additional dialectical behavioral therapy and psychopharmacological treatment prevented further weight loss and improved her affective state. Due to remaining anorexic symptoms such as body image distortion, outpatient psychotherapeutic treatment is continued. This case report indicates the importance of further research on diagnostic crossover from obesity to atypical anorexia nervosa.

\section{Introduction}

A diagnostic crossover from one eating disorder type to another in the course of eating disorders has repeatedly been reported in the literature [1-4]. Usually, crossovers between anorexia and bulimia nervosa are considered. We report a 15year-old, formerly obese, female adolescent who was referred to our day care clinic through a general practitioner due to significant self-induced weight loss and depressive symptoms.

\section{Case Report}

At the time of admission in August 2007 the patient's weight was $61.2 \mathrm{~kg}$ (69th percentile) with a height of $176 \mathrm{~cm}$ (94th percentile), which equates to a BMI of 19.8 (40th percentile). With a former weight of $100 \mathrm{~kg}$ in February 2007 , the patient lost $38.8 \mathrm{~kg}$ within a period of 4 months. A somatic reason for the weight loss was excluded.
In the case history, the patient and her mother stated that she started to continually gain weight at the age of 6 at school enrolment. They reported that the patient gradually ate more than usual, with an increase in size and number of meals; episodes of binge eating were negated. As the main reason, the patient stated frustration and the alcohol dependency of her mother and her mother's former partner. They started drinking at the patient's age of 5; at the patient's age of 8 the mother broke up the relationship with her partner and moved to another apartment with her daughter. The mother did not stop drinking until 2 years later at the patient's age of 10. At the time of her daughter's treatment, the mother was still hardly able to take care of her daughter, including her educational needs, due to her own massive mental problems. The maternal grandmother used to take over the patient's upbringing to a great extent, but due to her own multiple somatic diseases she was currently in need of help and unable to take care of the patient. Hence, the patient had to look after both her mother and her grandmother and support them throughout their daily routine. A familial risk of obesity exists as the mother is extremely overweight as well $\left(\mathrm{BMI}>30 \mathrm{~kg} / \mathrm{m}^{2}\right)$. We have no information about the biological father's weight category. The mother claimed the biological father, who hails from the former Yugoslavia, to be a 'one night stand'. They broke up during pregnancy.

The patient reported to have felt increasingly unattractive and ashamed of her obesity, especially when going swimming with peers. She, moreover, believed being thin would make her a better person, which led her to begin losing weight by restricting her nutrition in February 2007. She only had half an apple a day and drank low-caloric liquids (water and tea). Additionally, she started excessive physical exercise, such as jogging, gymnastics, and using the stairs whenever possible. She was not able to return to a normal eating behavior and reported an intense fear of gaining weight. Furthermore, the patient fulfilled the criteria of a distinctive body image distortion as she stated to experience herself as fat despite having normal body weight and overestimated her body parts (arm, thigh, leg) by about $150 \%$ when asked to estimate the circumferences using a string. The patient has been suffering from secondary amenorrhea for at least 3 months. Prior to amenorrhea, she had already been suffering from menstrual irregularities, despite not being underweight. No other somatic complications were ascertained. The patient fulfilled all ICD-10 criteria for anorexia nervosa, except for underweight. She was thus diagnosed with atypical anorexia nervosa. In addition to the eating disorder diagnosis, the patient reported to suffer from depressive symptoms, repetitive negative thinking, suicidal ideation, abdominal pain and head aches as well as obsessive-compulsive symptoms. The latter include repetitive

\section{KARGER}

Fax +497614520714

Information@Karger.de

www.karger.com (c) 2009 S. Karger GmbH, Freiburg

Accessible online at:

www.karger.com/ofa
Heike Wolter, MD

Department of Child and Adolescent Psychiatry, Psychosomatics and Psychotherapy

Charité, Universitätsmedizin Berlin - Campus Virchow-Klinikum

Augustenburger Platz 1, 13353 Berlin, Germany

Tel. +49 30/450 566210

heike.wolter@charite.de 
action, such as writing homework 6 times, and repeated hand washing. These symptoms first occurred in March 2007, during the phase of losing weight, and were regressed during treatment at our clinic.

At the beginning of inpatient treatment the patient ate extremely slowly very little amounts of food and chewed every bite for several minutes. She tried to reduce caloric intake by refusing to eat fat, such as butter, meat, cheese and so on, and by trying to avoid the suggested amounts of food. For the first two thirds of the therapy she received a strict calorie plan and had meals and portions prepared for her. At that stage of treatment the patient not only accepted the strict control but demanded it as she perceived it as helpful and supporting. Under the treatment her eating behavior continually improved. The patient maintained a constant body weight; moreover, a further weight loss was prevented. The distinctive depressive symptoms along with her suicidal ideation prompted us to treat the patient with escitalopram (Cipralex ${ }^{\circledR}$; Lundbeck GmbH, Hamburg, Germany) $10 \mathrm{mg}$, which resulted in an improvement of her depressive symptoms. Furthermore, the patient received individual and group therapy as well as body therapy. She participated in dialectical behavioral group therapy modified for eating disorders. After 3 months of day care clinic treatment, therapy has been continued in our outpatient eating disorder unit where the patient is still being therapeutically and psychiatrically supervised. In April 2008, at the age of 16 years, her latest measured weight amounted $63.2 \mathrm{~kg}$ at $178 \mathrm{~cm}$ body height (BMI $20.0 \mathrm{~kg} / \mathrm{m}^{2}, 39$ th percentile). Despite a normal weight, she still suffered from severe feelings of being fat and from amenorrhea.

\section{Discussion}

Diagnostic crossovers from obesity to (atypical) anorexia nervosa are not well examined. The course of the present case appears to be interesting as potentially many similar patients exist. However, a study on long-term stability of eating disorder diagnoses by Fichter and Quadflieg [5] shows no transits from mostly obese patients with binge eating diagnoses to anorexia nervosa diagnoses after 2, 6 and 12 years. An important aspect in diagnostic crossovers may be psychopatho- logical features. Tozzi et al. [6] found low novelty seeking, low self-directedness as well as high harm avoidance and low family cohesion to be related with a diagnostic crossover from bulimia to anorexia nervosa. The patient described in this case report suffered from depressive and obsessive-compulsive symptoms, including self-criticism, which are generally considered as 'typical' psychopathological traits in anorexia nervosa patients [7]. A recent study by Fenning et al. [8] claims selfcriticism as a key predictor for eating disorder symptoms. It seems as if anorexia nervosa-like psychopathological features can entail an unexceptionally large weight loss. In this regard, follow-up data on the stability of body weight in formerly obese patients who lost a lot of weight would be desirable. We assume that our patient will not maintain the diagnosis of an (atypical) anorexia nervosa, but rather regain weight due to the premorbid high BMI and the familial occurrence of obesity. For 'typical' anorexia nervosa patients, however, the BMI tends to remain low at follow-up [9].

This case report may underline the importance of personality and character traits for the development of eating disorders and diagnostic crossovers. It indicates the necessity of adequate eating disorder prevention in overweight patients. To date obesity has been considered a primarily somatic disorder and is not classified as an eating disorder. With regard to such crossovers, the adequateness of this dichotomy should be further discussed. More research on diagnostic crossovers between obesity and (atypical) anorexia nervosa is desirable, especially on larger samples.

\section{Disclosure}

The authors declared no conflict of interest.

\section{References}

1 Fichter MM, Quadflieg N, Hedlund S: Twelve-year course and outcome predictors of anorexia nervosa Int J Eat Disord 2006;39:87-100.

2 Fichter MM, Quadflieg N: Six-year course and outcome of anorexia nervosa. Int J Eat Disord 1999; 26:359-385.

3 Wentz E, Gillberg C, Gillberg IC, Rastam M: Tenyear follow-up of adolescent-onset anorexia nervosa: psychiatric disorders and overall functioning scales. J Child Psychol Psychiatry 2001;42:613-622.

4 Rastam M, Gillberg C, Wentz E: Outcome of teenage-onset anorexia nervosa in a Swedish community-based sample. Eur Child Adolesc Psychiatry 2003;12:78-90.
5 Fichter MM, Quadflieg N: Long-term stability of eating disorder diagnoses. Int J Eat Disord 2007; 40:61-66.

6 Tozzi F, Thornton LM, Klump KL, Fichter MM, Halmi KA, Kaplan AS, Strober M, Woodside DB, Crow S, Mitchell J, Rotondo A, Mauri M, Cassano G: Symptom fluctuation in eating disorders: correlates of diagnostic crossover. Am J Psychiatry 2005;162:732-740.

7 Steinhausen H-C: Anorexia nervosa. Göttingen, Hogrefe, 2005.
8 Fenning S, Hadas A, Itzhaky L, Roe D, Apter A, Shahar G: Self-criticism is a key predictor of eating disorder dimensions among inpatient adolescent females. Int J Eat Disord 2008;41:762-765.

$\checkmark 9$ Hebebrand J, Himmelmann GW, Herzog W, Herpertz-Dahlmann BM, Steinhausen H-C, Amstein M, Seidel R, Deter H-C, Remschmidt H, Schäfer $\mathrm{H}$ : Prediction of low body weight at long-term follow-up in acute anorexia nervosa by low body weight at referral. Am J Psychiatry 1997;154:566569. 